\title{
DIAGNOSTIC YIELD OF VARIOUS BRONCHOSCOPIC TECHNIQUES FOR EVALUATION OF LUNG CANCER: A RETROSPECTIVE ANALYSIS COMPARING ENDOBRONCHIALLY VISIBLE AND NON-VISIBLE LESIONS
}

\author{
Uday C. Kakodkar1, Akashdeep Singh Arora², Rohit Vadala ${ }^{3}$ \\ ${ }^{1}$ Associate Professor \& Unit Head, Department of Pulmonary Medicine, Goa Medical College, Goa. \\ 2 Senior Resident, Department of Pulmonary Medicine, Goa Medical College, Goa. \\ ${ }^{3}$ Ex. Senior Resident, Department of Pulmonary Medicine, Goa Medical College, Goa.
}

\section{ABSTRACT}

\section{BACKGROUND}

Flexible bronchoscopy is one of the main modalities for diagnosis of lung cancer and since in most centres of developing countries advanced guided bronchoscopic techniques are unavailable there is need to study the diagnostic yield of this procedure in the absence of imaging facilities like C-arm and EBUS.

\section{AIMS}

To compare the diagnostic yield of various bronchoscopic techniques in patients having en dobronchially visible lesion with those without any visible endobronchial growth. The specific aim of this retrospective study was to find whether in the absence of a visible endobronchial lesion one should do all the endoscopic procedures even if imaging modalities like C-arm or EBUS are not available.

\section{METHODS}

The patients of suspected bronchogenic carcinoma who underwent flexible video bronchoscopy during the 7-year period from Jan 2009 to Dec 2015 have been retrospectively analysed in this study; 514 bronchoscopies were analysed and 206 patients who fulfilled the inclusion criteria have been included in the present study.

\section{RESULTS}

Squamous cell carcinoma was the commonest histological diagnosis amongst endobronchially visible lesions, whereas it was poorly differentiated carcinoma when endobronchial growth was absent. The highest yield was by Endobronchial biopsy in the first group, while bronchial brush cytology provided maximum yield in the second group. There was a significant improvement in the diagnostic yield of flexible bronchoscopy when bronchial brush cytology and bronchial washings were combined, especially in those patients in whom there was no endobronchial lesion.

\section{CONCLUSIONS}

The cytological techniques like bronchial brush cytology and bronchial washings are useful in the diagnosis of endoscopically non-visible lung cancers in resource limited settings and should be routinely performed when advanced techniques are not available.

\section{KEYWORDS}

Flexible Bronchoscopy, Bronchogenic Carcinoma, Endobronchial Lesions.

HOW TO CITE THIS ARTICLE: Kakodkar UC, Arora AS, Vadala R. Diagnostic yield of various bronchoscopic techniques for evaluation of lung cancer: a retrospective analysis comparing endobronchially visible and non-visible lesions. J. Evolution Med. Dent. Sci. 2016; 5(43):2687-2692, DOI: $10.14260 /$ jemds/2016/628

\section{INTRODUCTION}

Lung cancer is estimated to soon become leading cause of cancer related mortality worldwide.[1] This is partly because unlike other cancers, lung cancer is detected mostly at an advanced stage when curative treatment options are limited. Early detection primarily depends on radiological screening followed by a cytological or preferably histopathological diagnosis.

There are two main modalities available to obtain the pathological sample in a patient with limited stage/curable disease, i.e. flexible bronchoscopy and by guided Transthoracic Fine Needle Aspiration Cytology (TTNA)/core biopsy (TTLB)

Financial or Other, Competing Interest: None.

Submission 13-04-2016, Peer Review 06-05-2016,

Acceptance 13-05-2016, Published 30-05-2016.

Corresponding Author:

Dr. Uday C. Kakodkar,

24, Azad Co-op. Housing Society,

Curca Tiswadi,

P. O. Goa Velha,

Goa-403108.

E-mail: drudayk@hotmail.com

DOI: $10.14260 /$ jemds/2016/628
The first is the domain of the pulmonologist, while the second is primarily the domain of the interventional radiologist. The incidence of pneumothorax is quite significant in patients subjected to transthoracic biopsy because of associated emphysema in lung cancer patients due to the common risk factor of smoking.[2] A transthoracic procedure will only give a pathological diagnosis, but a bronchoscopy will still be required in most cases prior to operative intervention for staging purpose. Hence, newer and more advanced guided bronchoscopic techniques are being designed for reaching out to even peripheral lung lesions, which were otherwise only accessible by TTNA/TTLB.

Most developed countries and many tertiary care centres in developing countries now routinely adopt guided bronchoscopic techniques for diagnosis of lung cancer, which include Endobronchial Ultrasound (EBUS) guided TTNA/TTLB, Electromagnetic Navigation Guided Bronchoscopic (EMNB) biopsy and fluoroscopy guided TBNA/TBLB at the least. However, the bulk of practising pulmonologists in developing countries like India still rely on the plain video-bronchoscope without any guidance due to non-availability of these costly equipment in majority of the centres. In such cases absence of an endobronchial growth significantly reduces chances of accessing the lesion 
accurately, thereby reducing the diagnostic yield of the procedure. It is of utmost importance to perform as much sampling of tissue from bronchial tree by combining procedures such as bronchial washings, bronchial brush cytology and cell block of bronchial washings to maximise the diagnostic yield.

\section{AIMS}

The aim of this retrospective analysis is to evaluate the diagnostic yield of endobronchial biopsy, bronchial washings, bronchial brush cytology and cell block of bronchial washings singly and in different combinations for pathological diagnosis of lung cancer in two subsets of patients - those with and without an endobronchially visible growth. We also aimed to study the pathological and clinical profile of the patients diagnosed as lung cancer in our tertiary care referral hospital.

\section{METHODS}

This study was conducted in the Department of Pulmonary Medicine, Goa Medical College, which is a tertiary care referral hospital. A retrospective analysis of the patient data of 514 patients who underwent flexible video-bronchoscopy from January 2009 till December 2015 was done. The patients admitted as suspected cases of bronchogenic carcinoma underwent bronchoscopy and were finally diagnosed to have lung cancer by any modality, which also included bronchoscopic procedures. Patients with proven final diagnosis of non-malignant primary lung disease, those with metastatic lung disease, patients lost to follow up with inadequate records were excluded from final analysis.

All the patients included in the study underwent flexible video-bronchoscopy after a standard pre-bronchoscopic evaluation, which included a chest X-ray with or without a CT scan of the thorax. Patients were divided into two groups on the basis of whether an endobronchial growth was visible or not during bronchoscopy. All patients underwent a varying combination of tissue sampling techniques, viz. endobronchial biopsy, bronchial washings and bronchial brush cytology. The bronchoscopic findings were categorised as normal study, presence of endobronchial growth, presence of mucosal irregularity and concentric narrowing of the bronchus.

In patients with visible endobronchial growth, a biopsy was taken from the growth under direct vision using the standard alligator/cupped biopsy forceps and the samples were immediately preserved in formalin solution. In patients without visible endobronchial growth, a biopsy was taken under direct vision from area of mucosal irregularity. Bronchial washings were collected by instilling around 20-30 cc of sterile saline solution in the affected segment (As analysed radiologically) and the returning fluid was aspirated into a mucus trap attached to the suction port of the scope. This fluid was then centrifuged at $5000 \mathrm{rpm}$ for 15 minutes and smears were made from the sediment and immediately preserved in CP fluid (Cytopathological analysis solution mixture of equal amounts formalin and ethanol).

The remainder of the sediment was suspended in Bouin's solution and a cellblock was made, which was then sent for histopathological analysis to the Department of Pathology. Bronchial brushings were taken from the areas of mucosal irregularity or blindly at times from the affected segment using the standard brush supplied with the scope. This brush was used to make smears on glass slides, which were preserved in $\mathrm{CP}$ fluid. The number of biopsies in individual patients varied from 2 to 5 . This variation was because of premature termination of the procedure in some patients due to either significant bleed following a biopsy or if the patient developed significant desaturation during the bronchoscopy. The study group consisted of patients who have been current or past smokers with associated COPD, barely maintaining $\mathrm{SpO} 2$ around $90 \%$ with supplemental oxygen.

The standard sequence of tissue sampling included Endobronchial Biopsy (EB) followed by Bronchial Washings (BW), finally the Brush Biopsy (BB) as the bleeding was maximum with brush biopsy in the study group. None of the patients developed any major complications during or in immediate post bronchoscopy period.

All slides were analysed by two independent and blinded pathologists to avoid any bias; only those samples which were definitely positive for malignancy have been included. The reports such as suspicious of malignancy or presence of dysplastic changes were not included in the final analysis. In case of discrepancy between cytological and histopathological report, the biopsy/cell block report was always relied upon and treatment decisions were taken on the basis of the same. The results were categorized as Small cell carcinoma, Squamous cell carcinoma, Adenocarcinoma, Poorly differentiated carcinoma, Large cell carcinoma, Carcinoid tumour and Positive for malignancy.

\section{RESULTS}

514 bronchoscopies were done for various indications from January 2009 till December 2015 in the Department of Pulmonary Medicine, Goa Medical College, Goa; 206 patients had histo/cyto-pathological confirmation of bronchogenic carcinoma and have been included in the final analysis as they were meeting the inclusion criteria of the present study.

20 patients had to undergo a repeat bronchoscopy to get the pathological diagnosis and only one patient out of these 209 was subjected to bronchoscopy third time in order to obtain pathological diagnosis.

The mean age of patients in our study was $61.01 \mathrm{yrs}$. with a standard deviation of $9.67 \mathrm{yrs}$. The median age was $60 \mathrm{yrs}$. There were 148 males and 58 females in the study population.

115 patients had endobronchially visible tumour, while in 91 patients the tumour was not visible through the bronchoscope. The distribution of the different histopathological types and their frequency in both groups is shown in Table 1.

\begin{tabular}{|c|c|c|c|}
\hline $\begin{array}{c}\text { The Cell } \\
\text { Type }\end{array}$ & $\begin{array}{c}\text { Endobronchial } \\
\text { Visible } \\
\text { Tumour }\end{array}$ & $\begin{array}{c}\text { Endobronchial } \\
\text { Non- } \\
\text { Visible } \\
\text { Tumour }\end{array}$ & Total \\
\hline $\begin{array}{c}\text { Squamous } \\
\text { Cell CA }\end{array}$ & 50 & 18 & 68 \\
\hline Adeno CA & 18 & 24 & 42 \\
\hline $\begin{array}{c}\text { Small Cell } \\
\text { CA }\end{array}$ & 11 & 3 & 14 \\
\hline $\begin{array}{c}\text { Poorly Diff } \\
\text { CA }\end{array}$ & 29 & 37 & 66 \\
\hline $\begin{array}{c}\text { POS for } \\
\text { Malignancy }\end{array}$ & 5 & 9 & 14 \\
\hline Others* & 2 & 0 & 2 \\
\hline Total & $\mathbf{1 1 5}$ & $\mathbf{9 1}$ & $\mathbf{2 0 6}$ \\
\hline
\end{tabular}

Table 1: The Distribution of Various Histopathological Types and the Endobronchial Visibility

* Others include a) Adenosquamous carcinoma - 1 
b) Signet ring carcinoma - 1

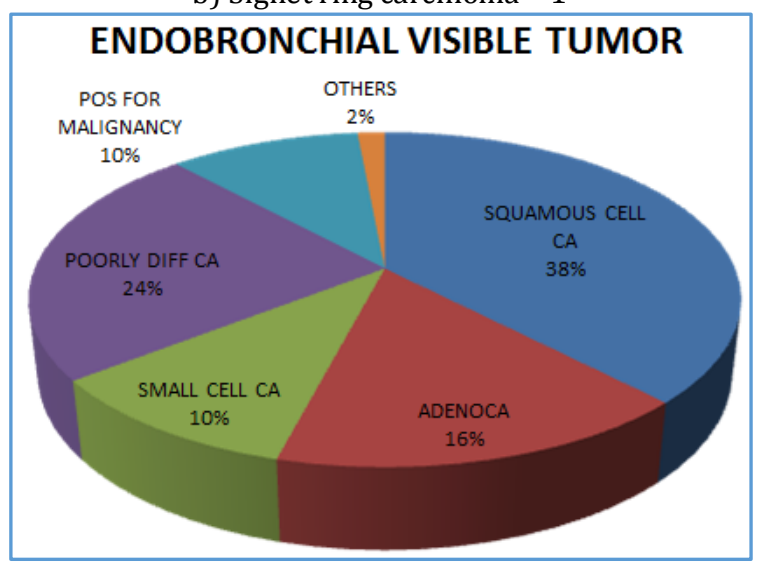

Fig. 1: The Pie Chart Depicting Distribution of Endobronchially Visible Tumour

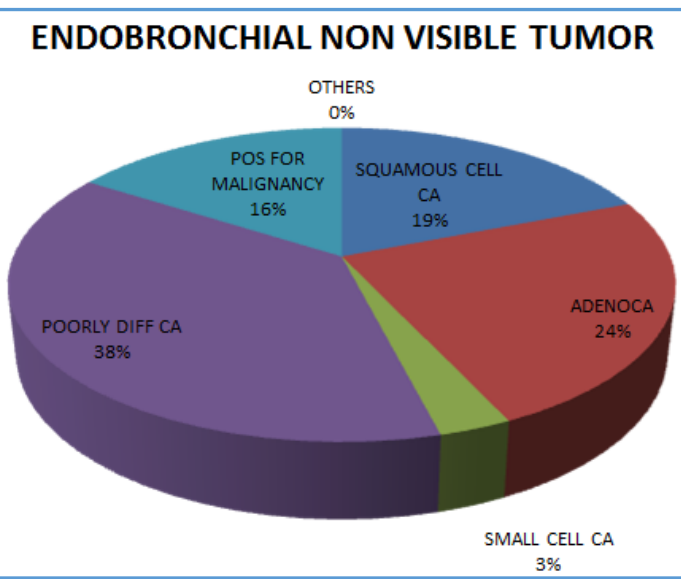

Fig. 2: The Pie Chart Depicting Distribution of Endobronchially Non-Visible Tumour

\begin{tabular}{|c|c|c|c|c|c|c|c|}
\hline & $\begin{array}{c}\text { Squamous } \\
\text { Cell } \\
\text { CA } \\
\end{array}$ & $\begin{array}{c}\text { Adeno } \\
\text { CA }\end{array}$ & $\begin{array}{c}\text { Small } \\
\text { Cell } \\
\text { CA } \\
\end{array}$ & $\begin{array}{c}\text { Poorly } \\
\text { Diff } \\
\text { CA }\end{array}$ & $\begin{array}{l}\text { Positive for } \\
\text { Malignancy }\end{array}$ & Others & Total \\
\hline EBB & 46 & 13 & 10 & 28 & 6 & 2 & 105 \\
\hline BW & 20 & 8 & 5 & 16 & 13 & 0 & 62 \\
\hline $\mathrm{BB}$ & 13 & 13 & 6 & 26 & 14 & 0 & 72 \\
\hline $\mathrm{CB}$ & 16 & 7 & 4 & 9 & 2 & 0 & 38 \\
\hline TBNA & 1 & 1 & 0 & 1 & 0 & 0 & 3 \\
\hline TBLB & 1 & 2 & 0 & 0 & 0 & 0 & 3 \\
\hline CT FNAC & 8 & 7 & 1 & 12 & 0 & 0 & 28 \\
\hline LN FNAC & 1 & 7 & 0 & 0 & 0 & 0 & 8 \\
\hline PL FLUID CP/HP & 1 & 3 & 0 & 1 & 2 & 0 & 7 \\
\hline OTHERS & 1 & 0 & 1 & 2 & 0 & 0 & 4 \\
\hline
\end{tabular}

*others include a) Postmortem lung biopsy - squamous cell - ca - 1

b) Post bronchoscopy sputum cytology-small cell ca - 1

EBB - Endobronchial Biopsy, BW - Bronchial Washing, BB - Bronchial Brushing, CB - Cell Block, TBNA - Transbronchial Needle Aspiration, TBLB - Transbronchial Lung Biopsy, CT FNAC - CT-guided Fine Needle Aspiration Cytology, LN FNAC - FNAC of lymph node, PL Fluid CP/HP - Cytology of Pleural Fluid or ultrasound-guided FNAC of pleural deposits.

\begin{tabular}{|c|c|c|c|c|}
\hline & $\begin{array}{l}\text { Endobronchial } \\
\text { Visible Tumour }\end{array}$ & $\begin{array}{c}\text { Endobronchial Non-Visible } \\
\text { Tumour }\end{array}$ & Total & $\%(n=206)$ \\
\hline EBB & 88 & 17 & 105 & 50.97 \\
\hline BW (SMEARS) & 36 & 26 & 62 & 30.1 \\
\hline BB & 35 & 37 & 72 & 34.95 \\
\hline BW (CELL BLOCK) & 30 & 8 & 38 & 18.44 \\
\hline TBNA & 0 & 3 & 3 & 1.45 \\
\hline TBLB & 0 & 3 & 3 & 1.45 \\
\hline PLEURAL FLUID CP & 3 & 4 & 7 & 3.39 \\
\hline CT GUIDED FNAC & 7 & 21 & 28 & 13.59 \\
\hline $\begin{array}{l}\text { CERVICAL } \\
\text { LN FNAC }\end{array}$ & 2 & 6 & 8 & 3.88 \\
\hline OTHERS* & 0 & 4 & 4 & 1.93 \\
\hline \multicolumn{5}{|c|}{$\begin{array}{l}\text { Table 3: Distribution of Location of the Tumour } \\
\text { and Various Procedures Leading to Diagnosis }\end{array}$} \\
\hline
\end{tabular}

*Others include diagnosis by, a) Post mortem lung biopsy - 1

b) Post bronchoscopic sputum cytology - 3

In all the 4 cases of this group, no tumour was visible endobronchially. 


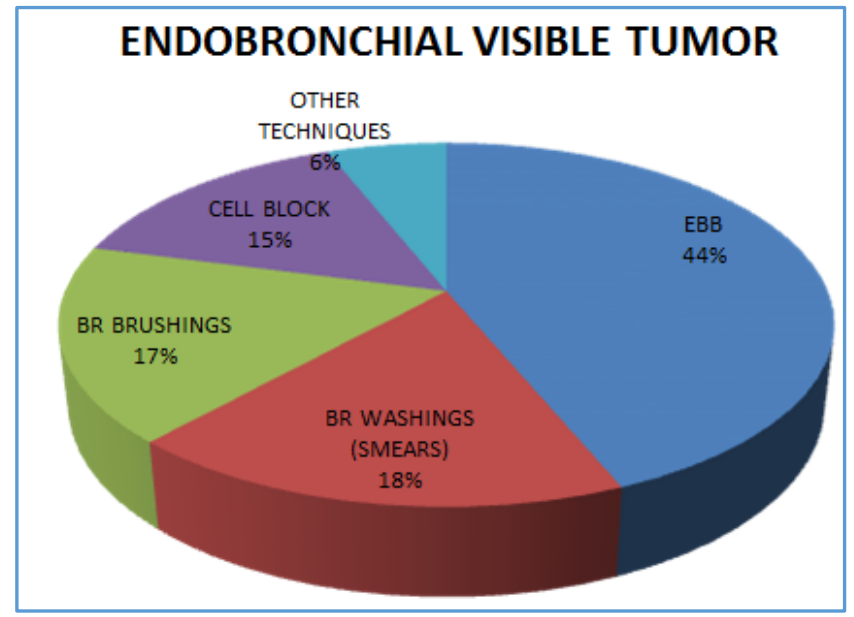

Fig. 3: The Pie Chart Depicting Diagnostic Yield of Various Diagnostic Procedures in Endobronchially Visible Tumour

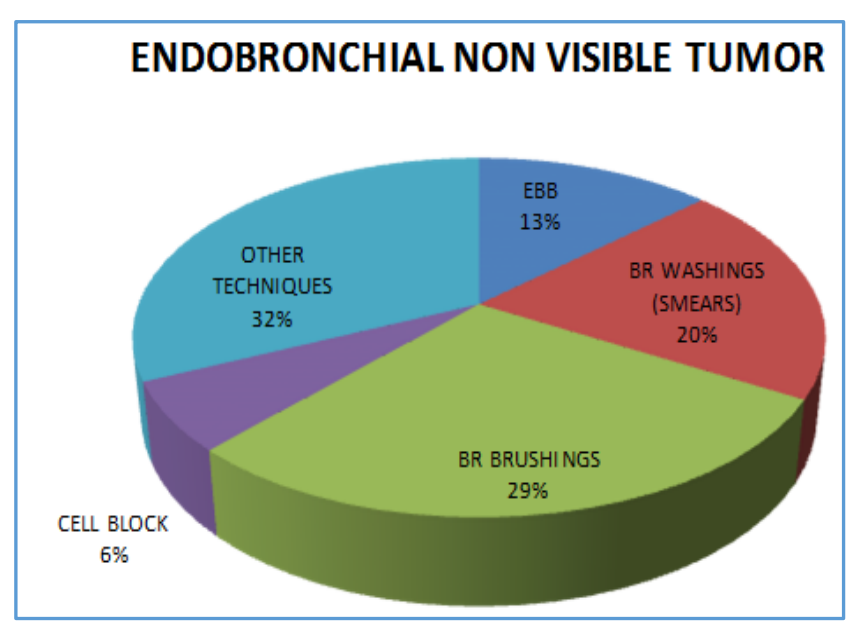

Fig. 4: The Pie Chart Depicting Diagnostic Yield of Various Diagnostic Procedures in Endobronchially Non-Visible Tumour

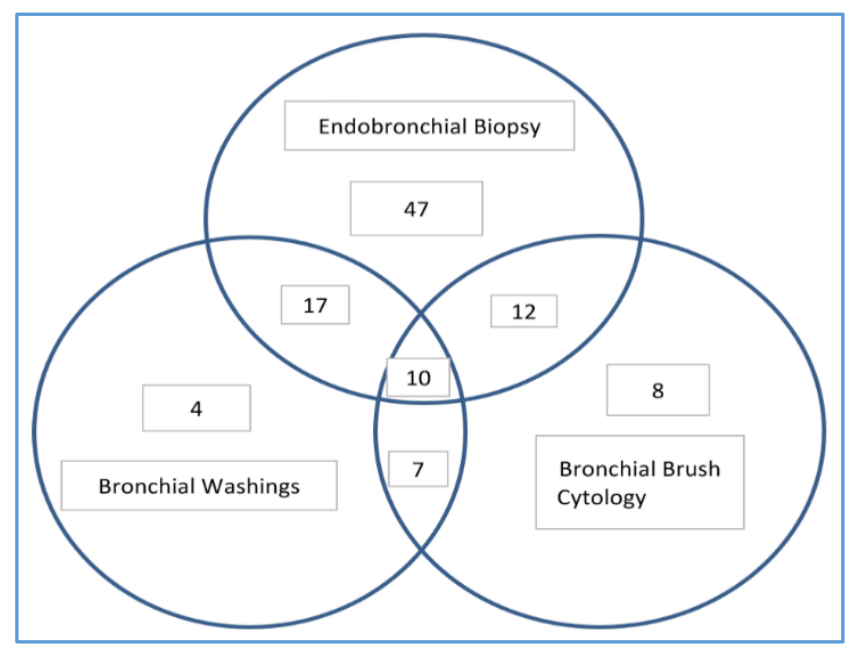

Fig. 5: Diagram showing Diagnostic Yield of Different Bronchoscopic Techniques Alone and in Combination in Patients with Endobronchial Visible Growth $(n=115)$

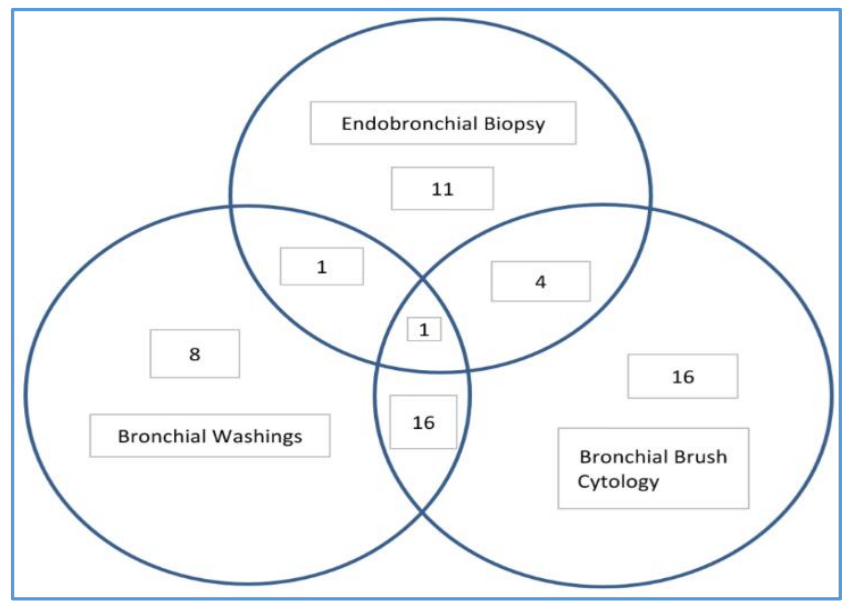

Fig. 6: Diagram showing Diagnostic Yield of Different Bronchoscopic Techniques Alone and in Combination in Patients with Endobronchial Non-Visible Growth $(n=91)$

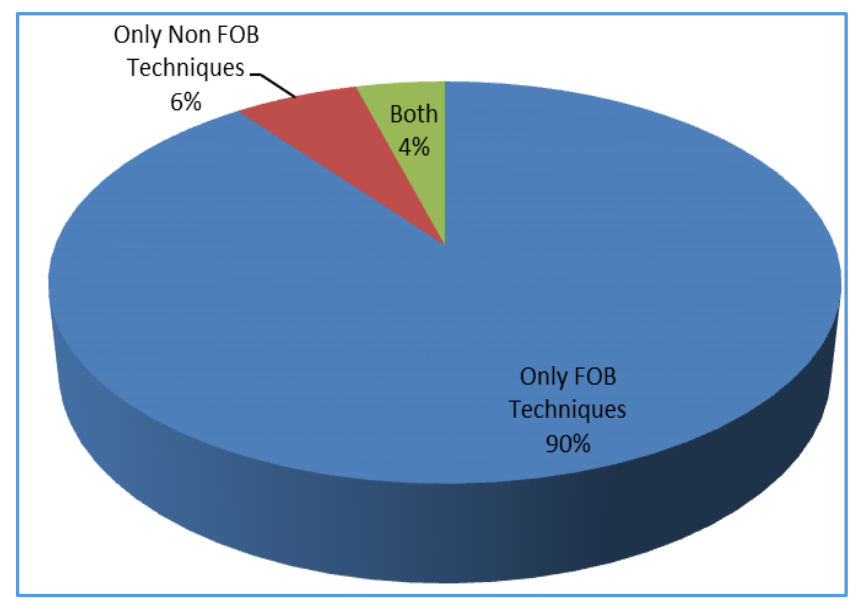

Fig. 7: The Pie Chart Depicting Comparison of Diagnostic Yield of Bronchoscopic vs Non-Bronchoscopic Procedures in Endobronchially Visible Tumours

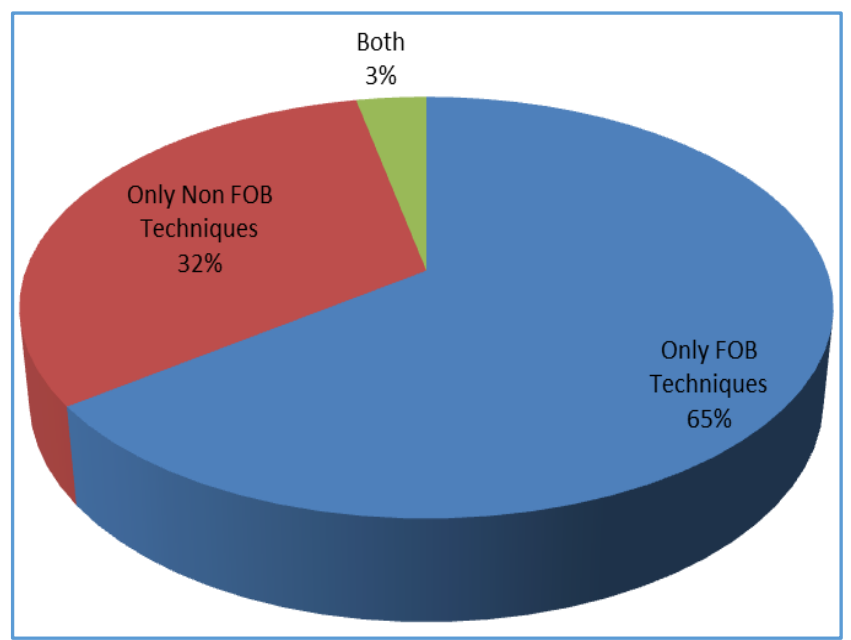

Fig. 8: The Pie Chart Depicting Comparison of Diagnostic Yield of Bronchoscopic vs Non-Bronchoscopic Procedures in Endobronchially Non-Visible Tumours 


\begin{tabular}{|c|c|c|}
\hline FOB Findings & No. & \% \\
\hline Normal bronchoscopy & 8 & 3.88 \\
\hline Abnormal Bronchoscopy & & \\
\hline Endobronchial growth & 115 & 55.82 \\
\hline Mucosal irregularity & 70 & 33.98 \\
\hline Concentric narrowing & 62 & 30.09 \\
\hline Table 4: Distribution of Bronchoscopic \\
Findings in the Study Population \\
\hline
\end{tabular}

\section{DISCUSSION}

Lung cancer is one of the most common malignancies with high mortality; $13 \%$ of all new cancer cases and $19 \%$ of all cancer related deaths worldwide are due to lung cancer; $6.9 \%$ of all new cancer cases and $9.3 \%$ of all cancer related deaths in India are due to lung cancer; 5-year survival rate is only $15 \%$ in the developed countries and a dismal $5 \%$ in the developing countries.[3]

We found a male:female ratio of 2.55:1 amongst our study population. As per ICMR cancer registry statistics till mid2002, the male:female ratio was 4.5:1 in India. Mufti et al[ ${ }^{4]}$ also found a male:female ratio of 4.4:1. Choudhury et al[5] found a male:female ratio of 3.3:1 in their study conducted in Delhi. There is an alarming increase in the incidence of lung cancers in women and consequently its mortality in USA. This has been attributed to rise in smoking trends in US women in 1970s.[3] Ferlay et al[6] also made similar observations about rising incidence amongst women in developed nations relating it to increase in smoking habits amongst women. This could be due to the fact that in India prevalence of female smoking is not as high as it is globally.[7] Secondly, the study group represents selected population of patients admitted to a tertiary care hospital and may not be truly representative of the scenario in general population.

Behera.[7] found that squamous cell carcinoma was the most common histopathological subtype amongst lung cancers in India followed by adenocarcinoma. Rabahi et al[8] also found that amongst endobronchially visible tumours, squamous cell carcinoma was commonest subtype, whereas adenocarcinoma was commonest subtype amongst the endobronchially non-visible tumours. Buccheri et al[9] found that squamous cell carcinomas were mainly central tumours, whereas adenocarcinomas were mainly peripheral. Khunjeli et al[10] also found squamous cell carcinoma to be the commonest histological subtype. In our study too, the commonest histopathological diagnosis amongst endobronchial visible tumours was squamous cell carcinoma. The commonest histopathological subtype amongst endobronchially nonvisible tumours in our study was poorly differentiated carcinoma. This is likely to be explained on the basis that most of the pathological diagnoses in this study subgroup were made by bronchial brushings and washings, in which cell concentration was lesser compared to that of a biopsy specimen and hence the cell diagnosis could not be accurately determined, so a predominance of poorly differentiated carcinoma was noted in this subgroup.

Buccheri et al[9] found that squamous cell and small cell carcinomas were mainly central tumours, whereas adenocarcinomas were mainly peripheral tumours. In our study also we found that squamous cell and small cell carcinomas were predominantly found in the first group, whereas adenocarcinomas and poorly differentiated carcinomas were predominant in the second group, thereby reiterating the fact that location of the mass can give a clue to likely histological subtype.

Liam et al[11] reported a diagnostic yield of $71.2 \%$ for endobronchially visible tumours and $43.6 \%$ for endobronchially non-visible tumours. The average reported sensitivity of bronchoscopy for peripheral lesions, which are not endobronchially visible is $70 \%$ when fluoroscopy is routinely used and $38 \%$ (range 28\%-56\%) when bronchoscopy is performed without fluoroscopy guidance.[12] In our study, we found a diagnostic yield of $94 \%$ in first group and $68 \%$ in the second group even in the absence of fluoroscopic guidance.

Labbe et al[13] found that the overall diagnostic yield of non-guided bronchoscopy was $25.6 \%$ for endobronchially non-visible tumours. Brushing yielded highest diagnostic yield (16.4\%) compared to aspiration (14.0\%) and BAL (11.6\%), although the differences between the various techniques were not statistically significant $(p=0.08)$. Bodh et al[14] and Stringfield et al[15] recommended the use of bronchial washings and brushings in addition to biopsy to increase the diagnostic yield. In our study, we found the diagnostic yield in the endobronchially non-visible group to be highest for bronchial brushings (40.65\%) followed by bronchial washings $(28.57 \%)$ and lastly by endobronchial biopsy (18.6\%). These observations therefore emphasise the importance of these bronchoscopic techniques for cytological diagnosis even in endobronchially non-visible tumours. This is very heartening as most of the centres in India are not equipped with imaging modalities during bronchoscopy to locate a peripheral lesion.

Schrieber and McCrory.[16] did a review of published studies on the diagnostic yield of different bronchoscopic techniques for lung cancer and found the average diagnostic yield for EBB, BB and BW as between 48-97\%, 23-93\% and $29-78 \%$ respectively. Mak et al[17] found the diagnostic yield of endobronchial biopsy to be highest in endobronchially visible tumours at $76 \%$ followed by bronchial brushings (52\%) and bronchial washings (49.4\%). Liam et al[11] found the diagnostic yields for EBB, BB and BW were $77.5 \%, 53.7 \%$ and $28.3 \%$ respectively in patients with visible endobronchial tumours. In our study too, we found the diagnostic yield of endobronchial biopsy in this group to be highest at $74.8 \%$ followed by bronchial washings $(33.04 \%)$ and bronchial brushings (32.17\%). Mak et al found the diagnostic yield of bronchial washings to be highest (38\%) in endobronchially non-visible tumours followed closely by EB (36.5\%) and BB (28\%). Liam et al[11] found yields from bronchial washings and brushings of $35.5 \%$ and $22.9 \%$ respectively in the endobronchially non-visible tumour group. In our study, we found the diagnostic yield in the endobronchially non-visible group to be highest for bronchial brushings ( $40.65 \%)$ followed by bronchial washings (28.57\%) and lastly by endobronchial biopsy (18.6\%). Popp et al[18] found that the sensitivity of endobronchial forceps biopsy significantly reduced in endobronchial non-visible tumour group compared to the endobronchial visible tumour group. We also found similar findings, as the diagnostic yield of forceps biopsy was $74.8 \%$ in the first group, but only $18.6 \%$ in the second group.

Kvale et al[19] found no additional advantage of BW over a combination of BB and EBB. Dasgupta et al [20] found BW to be least useful of the three bronchoscopic diagnostic techniques. Some studies have reported that adding BW to EBB and BB increases the diagnostic yield.[9,17,21], whereas others have 
reported no additional value of BW. In our study, we found the isolated yield of bronchial washings the lowest in both groups; however, it was the only positive diagnostic modality in 3.5\% and $8.8 \%$ of cases in first and second group respectively. This is likely to be because of the low cellularity of bronchial washing fluid because of low volume of sample. Considering that performing the washings is not a very costly addition to the entire procedure cost, but at the same time can even mildly improve diagnostic yield in a resource limited setting like ours. We feel it would be worthwhile to perform it routinely in all such diagnostic bronchoscopies.

We found that the diagnostic yield of fiberoptic bronchoscopy was significantly more in the first group, that is when an endobronchial growth is visible. The concurrent use of all three main bronchoscopic techniques is advisable as per our results in order to maximise the diagnostic yield of fiberoptic bronchoscopy for primary lung malignancies. Similar observations were noted by Khunjeli et al[10] and Popp et al[18] too.

\section{CONCLUSIONS}

A combination of all three basic bronchoscopic procedures, viz. endobronchial biopsy, bronchial washings and bronchial brush cytology is the best way to maximise the diagnostic yield in a suspected case of pulmonary neoplasm. It is definitely worthwhile to do the above diagnostic techniques even in patients where there is no visible endobronchial growth as seen from the results of the present study.

This has significant relevance for developing world as most of the centres do not have very expensive imaging equipment like EBUS or Electromagnetic guided Bronchoscopy (EMNB).

\section{ACKNOWLEDGEMENT}

The authors would like to thank the Dean, Goa Medical College, Goa, for permitting us to conduct this study.

\section{REFERENCES}

1. Stewart BW, Wild CP. World cancer report 2014. International agency for research on cancer. World Health Organization 2014.

2. Boskovic T, Stanic J, Pena-Karan S, et al. Pneumothorax after transthoracic needle biopsy of lung lesions under CT guidance. Journal of Thoracic Disease 2014;6(1):S99S107. doi:10.3978/j.issn.2072-1439.2013.12.08.

3. Malik PS, Raina V. Lung cancer: prevalent trends and emerging concepts. Ind J Med Res 2015;141(1):5-7.

4. Mufti ST, Mokhtar GA. Diagnostic value of bronchial wash, bronchial brushing, fine needle aspiration cytology versus combined bronchial wash and bronchial brushing in the diagnosis of primary lung carcinomas at a tertiary care hospital. Biomedical Research 2015;26(4):777-84.

5. Choudhury M, Singh S, Agarwal S. Efficacy of bronchial brush cytology and bronchial washings in diagnosis of non-neoplastic and neoplastic bronchopulmonary lesions. Turk Patoloji Derg 2012;28(2):142-6.

6. Ferlay J, Shin HR, Bray F, et al. Estimates of worldwide burden of cancer in 2008: GLOBOCAN 2008. Int J Cancer 2010;15(127):2893-917.
7. Behera D. Epidemiology of lung cancer-global and Indian perspective. J Indian Acad Clin Med 2012;13:131-7.

8. Rabahi MF, Ferreira AA, Reciputti BP, et al. Fiberoptic bronchoscopy findings in patients diagnosed with lung cancer. J Bras Pneumol 2012;38(4):445-51.

9. Buccheri G, Barberis P, Delfino MS. Diagnostic, morphologic, and histopathologic correlates in bronchogenic carcinoma. A review of 1,045 bronchoscopic examinations. Chest 1991;99(4):809-14.

10. Khunjeli R, Shrestha SK, Karki M, et al. Radiological and bronchoscopic findings for the better yield of tissue diagnosis in lung malignancy. Medical Journal of Shree Birendra Hospital 2015;13(2):25-30.

11. Liam CK, Pang YK, Poosparajah S. Diagnostic yield of flexible bronchoscopic procedures in lung cancer patients according to tumour location. Singapore medical journal 2007;48(7):625-31.

12. Detterbeck FC, Rivera MP. Clinical presentation and diagnosis. In: Detterbeck FC, Rivera MP, Socinski MA, Rosenma JG, eds. Diagnosis and treatment of lung cancer. Philadelphia, WB Saunders Co 2001;1 ${ }^{\text {st }}$ edn:45-72.

13. Labbé C, Beaudoin S, Martel S, et al. Diagnostic yield of non-guided flexible bronchoscopy for peripheral pulmonary neoplasia: bronchoscopy \& amp; peripheral lung cancer. Thoracic Cancer 2015;6(4):517-23.

14. Bodh A, Kaushal V, Kashap S, et al. Cytohistological correlation in diagnosis of lung tumours by using fiberoptic bronchoscopy: study of 200 cases. Indian J Pathol Microbiol 2013;56(2):84-8.

15. Stringfield JT, Markowitz DJ, Bentz RR, et al. The effect of tumour size and location on diagnosis by fiberoptic bronchoscopy. Chest 1977;72(4):474-6.

16. Schreiber G, McCrory DC. Performance characteristics of different modalities for diagnosis of suspected lung cancer: summary of published evidence. Chest 2003;123(1):115S-28S.

17. Mak VH, Johnston ID, Hetzel MR, et al. Value of washings and brushings at fibreoptic bronchoscopy in the diagnosis of lung cancer. Thorax 1990;45(5):373-6.Popp W, Rauscher H, Ritschka L, et al. Diagnostic sensitivity of different techniques in the diagnosis of lung tumours with the flexible fiberoptic bronchoscope. Comparison of brush biopsy, imprint cytology of forceps biopsy, and histology of forceps biopsy. Cancer 1991;67(1):72-5.

18. Kvale PA, Bode FR, Kini S. Diagnostic accuracy in lung cancer: comparison of techniques used in association with flexible fibreoptic bronchoscopy. Chest 1976;69(6):752-7.

19. Dasgupta A, Jain P, Minai OA, et al. Utility of transbronchial needle aspiration in the diagnosis of endobronchial lesions. Chest 1999;115(5):1237-41.

20. Lam WK, So SY, Hsu C, et al. Fibreoptic bronchoscopy in the diagnosis of bronchial cancer: comparison of washings, brushings and biopsies in central and peripheral tumours. Clin Oncol 1983;9(1):35-42. 